\title{
CRANE OPERATING FIELD CONTROL SYSTEM
}

\author{
Jun Nishimura, Kazumi Okuzumi,Takaji Imamura, Tomio Kishino \\ Shimizu Corporation \\ No.2-3,Shibaura 1-chome,Minato-ku,Tokyo 105-07,Japan
}

\begin{abstract}
Based on conditions in the area surrounding a site, in certain cases constraints apply to the use of cranes in construction. Such cases include sites very close to a road, railway line, power transmission line, or another building, as well as sites where legal restrictions such as civil aeronautics law apply.

The crane operating field control system uses an automatic tracking total station to measure in real time the position of the end of a crane's boom. The operating range of the crane is set by a computer which uses data on the real time position of the boom to determine whether it is within the safe area. The computer can set multiple and complex operating ranges as well store operational data and warning signal data, information which can be applied to future work.
\end{abstract}

\section{INTRODUCTION}

Cranes have a diverse range of applications at construction sites. In certain cases constraints apply to the use of cranes in construction, such as when a site is very close to a road, railway line, power transmission line, or another building. Also, since height restrictions based on civil aeronautics law vary from site to site, and these heights cannot be visually determined accurately, monitoring devices developed to date and human monitors are inadequate means of ensuring crane booms do not breach restrictions.

Given this background, we have developed the crane operating field control system for safe and sure crane work on sites subject complex restrictions. This report outlines the system and provides an example application at a construction site.

\section{SYSTEM OUTLINE}

The prism at the end of the boom is automatically tracked by a total station so that the position $(X, Y, Z)$ of the end of the boom is always known. The position $(X, Y$, $Z$ ) of the end of the boom, which is output from the total station, is processed by an area judgment device into which is inserted a memory card containing information on the operating range of the crane that is preset by the computer. 
The area judgment device calculates all restriction values $X \max , Y \max , Z \max$ for the site using position data $(X, Y, Z)$ provided by the total station. By comparing calculated values (Xmax, Ymax, Zmax) and $X, Y$, and $Z$ position data $(X, Y, Z)$ output by the total station, the device can determine whether or not the end of the boom is in the safe area.

When $X \leq X \max , Y \leq Y \max$, or $Z \leq Z \max$, the end of the boom is in the safe area. When $X>X \max , Y>Y \max$, or $Z>Z$ max, the end of the boom is out of the safe area, and a signal is sent by radio to a warning device in the operation cab which emits a sound to warn the operator. The operation record of each day is stored in a memory card so operational data and warning signal data can be checked by a computer in the office.

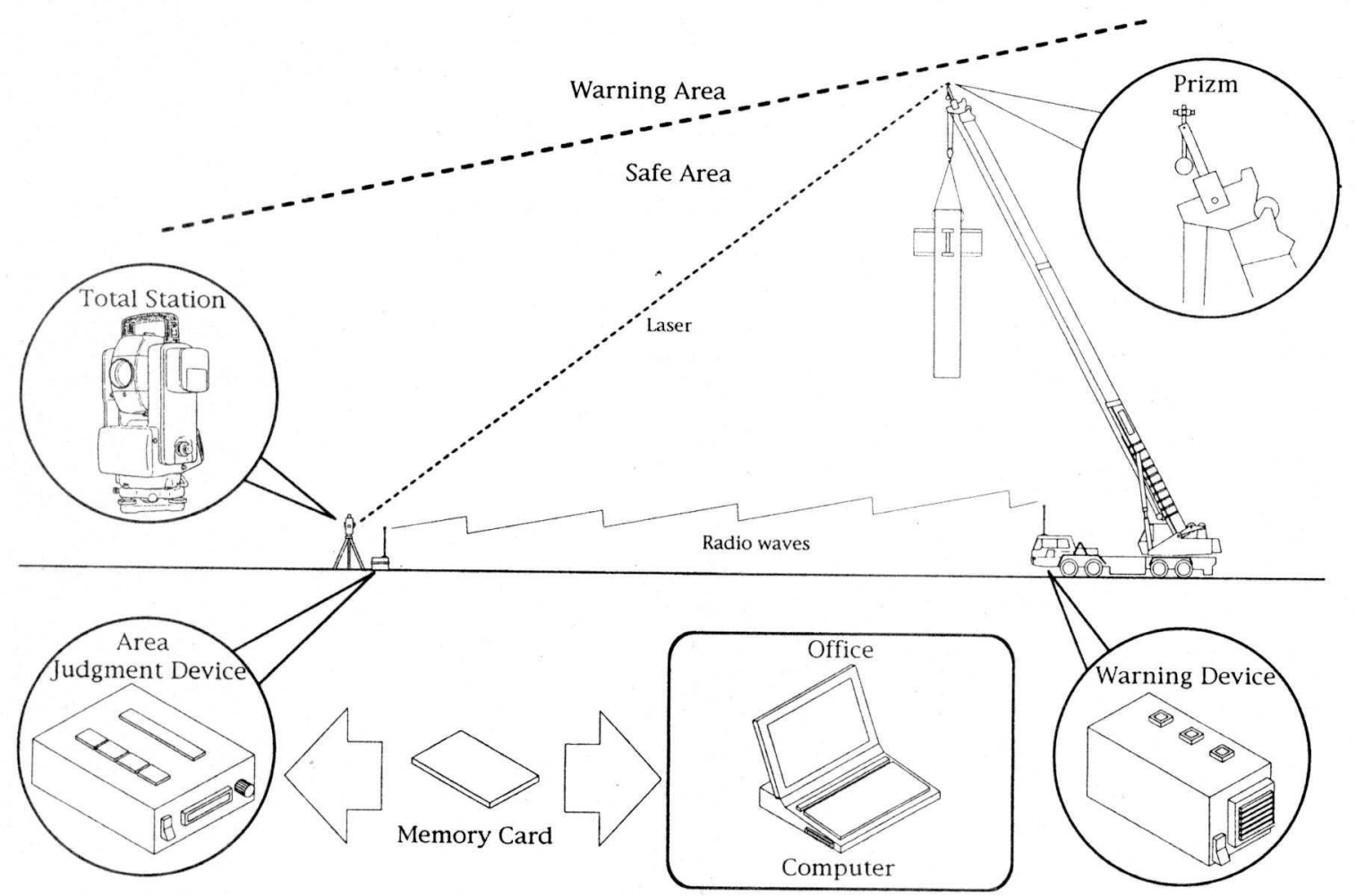

Figure 1 System diagram

\section{SYSTEM CONFIGURATION DEVICE}

\section{1) Prism}

A prism is installed at the end of the boom. The jig holding the prism is a pendulum that remains horizontal at all boom hoisting angles (see Figure 2).

The total station can detect the prism at $\pm 30^{\circ}$. If automatic tracking is performed out of this range, the total station may not be able to detect the prism. Therefore, prism jigs with inclinations of $0^{\circ}, 15^{\circ}$, and $30^{\circ}$ have been designed and the one most appropriate for the situation is selected (see Figure 3). 


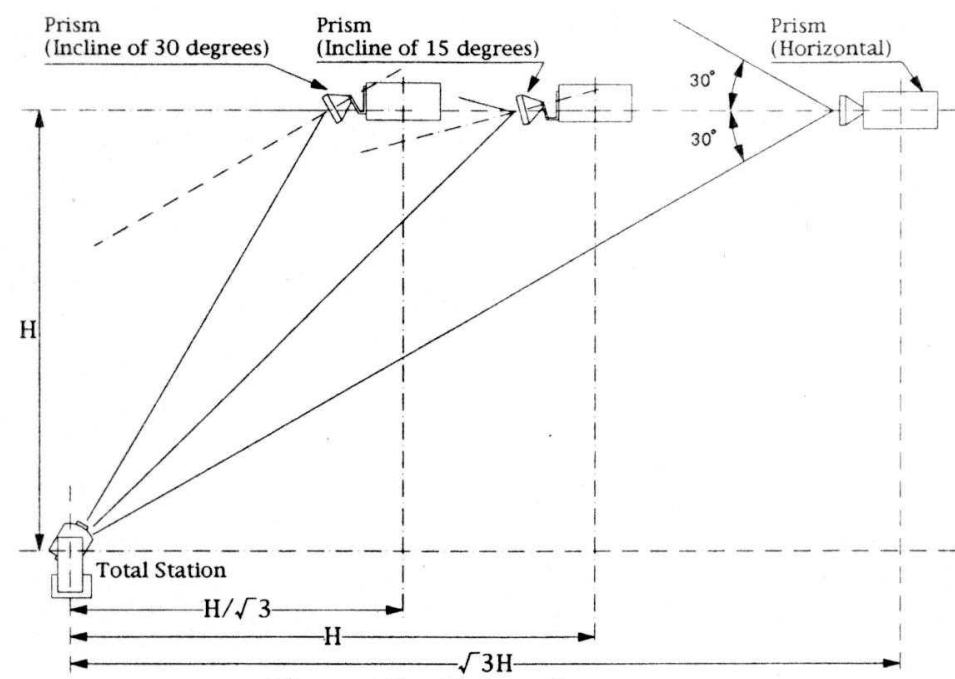

Figure 3 Prism jig

\section{2) Total station}

The total station automatically tracks the prism on the end of the boom and transfers tracking data to the area judgment device about once a second.

\section{3) Area judgment device and transmitter}

The area judgment device checks whether the end of the boom is in the safe area by using position data $(X, Y$, and $Z)$ transferred from the total station. If it isn't, a transmitter sends signals to a warning device. Judgment criteria are set by a computer in the office and input into the area judgment device which contains a memory card. Reference point positions, the installation position of the total station, and the initial settings of the total station are also input into the area judgment device at the same time.

All position data transmitted from the total station are stored in a memory card so operational data and warning signal data can be checked by a computer in the office after the work is done.

4) Warning device and receiver

The receiver receives signals from the area judgment device's transmitter and, if necessary, the warning device emits a warning sound.

\section{5) Computer}

The computer inputs, outputs, and processes the following items:

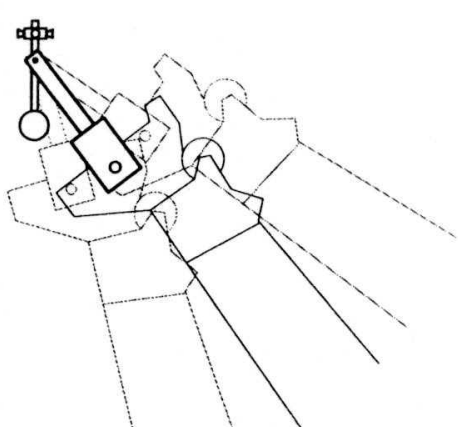

Figure 2 Pendulum jig

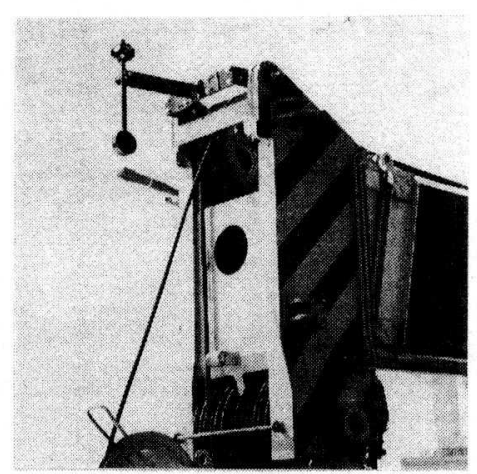

Figure 4 Prism

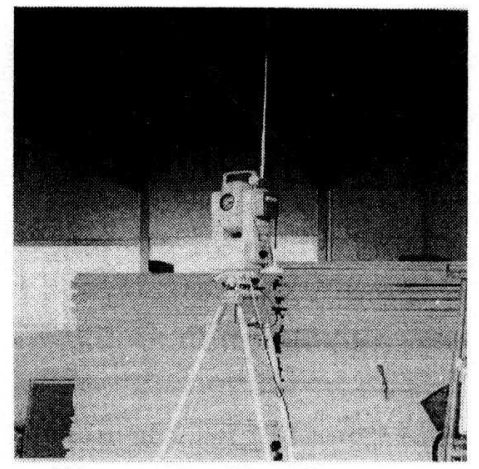

Figure 5 Total station

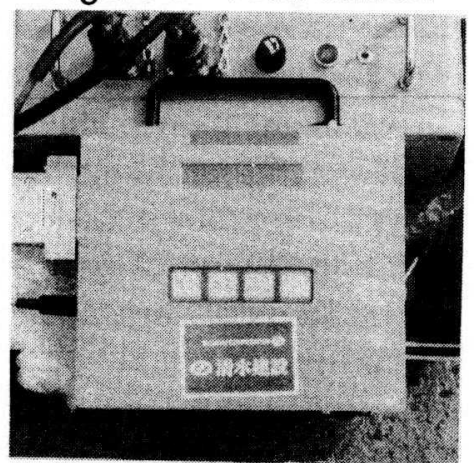

Figure 6 Area judgment

device 
(1) Initial settings

1) Reference point coordinates

Reference points are input to calculate the installation position of the total station. The total station calculates the installation position by collimating any two reference points. A maximum of 16 reference points can be registered.

\section{2) Warning area coordinates}

The warning area is input. A maximum of 10 monitoring ranges can be registered.

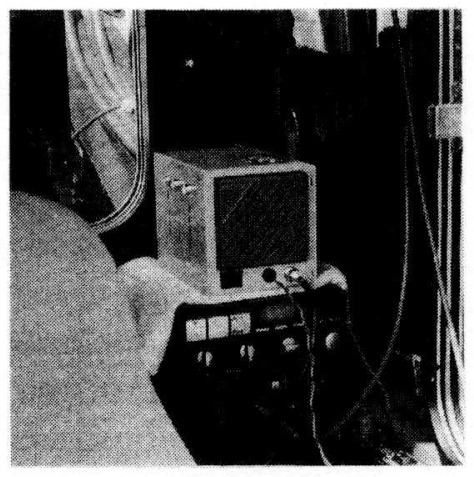

Figure 7 Warning device

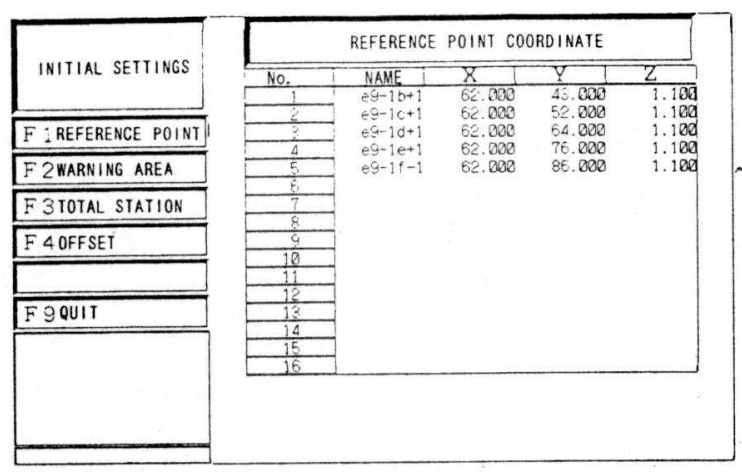

Figure 8 Reference point

coordinate screen

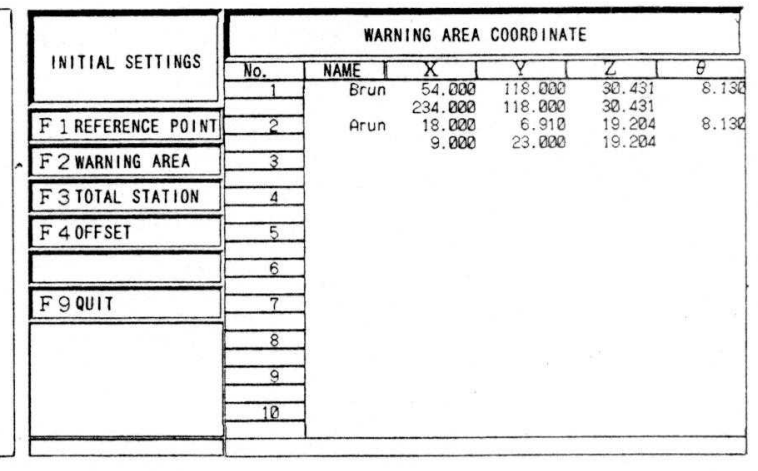

Figure 9 Warning area

coordinate screen

\section{3) Total station}

The initial settings of the total station are input.

\section{4) Offset input}

The offset of the warning area is input.

(2) Processing before work

1) Total station coordinates

The installation position of the total station is selected. If it is not, it is calculated by collimating reference points.

2) Initialization of the memory card

The memory card is initialized.

3) Writing of the memory card

Data set is written in the memory card, which is installed in the area judgment device. 
(3) Processing after work

1) Reading of the memory card

Operation data transferred from the area judgment device is read onto a computer.

2) Data display

Operations data and warning signal data are displayed.

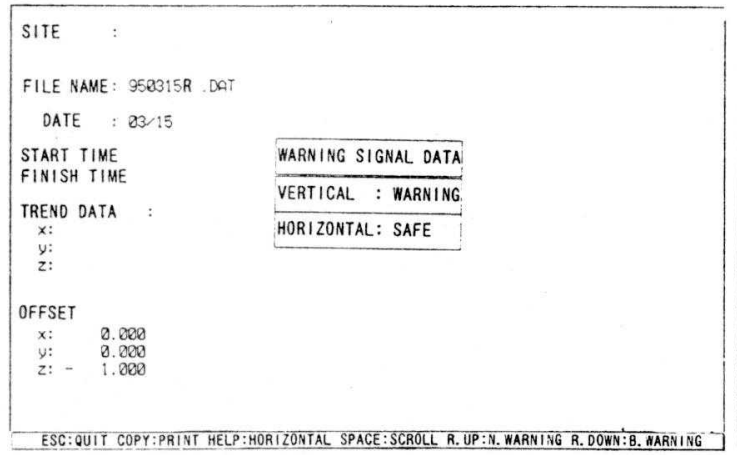

Figure 10 Warning signal data screen

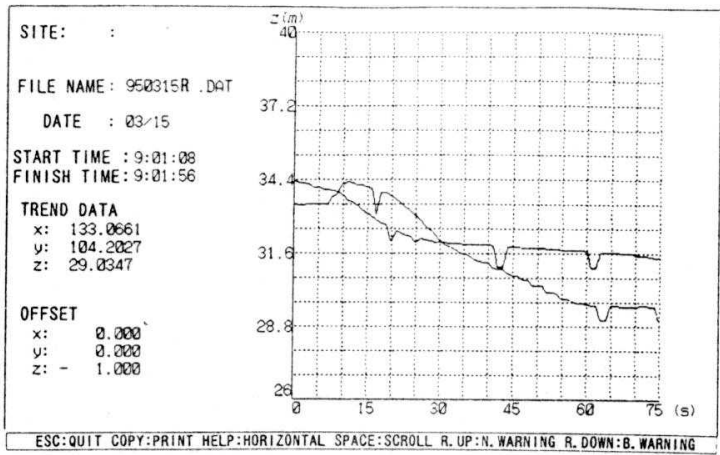

Figure 11 Operations data screen

3) Saving data

Operations data is saved on floppy disks.

\section{METHOD OF SETTING THE WARNING RANGE}

The warning area is set by setting its boundary plane. This is done by inputting two points (point $S$ and point $G$ ) of equal elevation which touch the boundary plane and by arranging the boundary plane at an angle $\alpha$. As Figure 12 shows, inputting vector is from point $S$ (Xs, Ys, Zs), the first to be input, to point $G(X g, Y g, Z g)$, the second to be input. The warning area is set to the right of the vector direction. When the coordinate input point is from Point $G$ to Point $S$, the positions of the warning area and the safe area are reversed.

Figure 13 shows a case in which the boundary plane is set vertically $\left(\alpha=90^{\circ}\right)$. With this setting the warning area and the safe area can be divided with the $X-Y$ plane.

Figure 14 shows a case in which the boundary plane is set horizontally $\left(\alpha=0^{\circ}\right)$. With this setting the warning area and the safe area can be divided with the $Z$ axis.

Figure 15 shows a case in which the boundary plane is set at the angle $0^{\circ}<\alpha<$ $90^{\circ}$. When the calculated angle $\alpha^{\prime}$ is $\alpha^{\prime}>\alpha$, the position is considered in the warning area. When the calculate angle is $\alpha^{\prime}<\alpha$, the position is considered in the safe area.

With the above examples, the warning area can be set by inputting any two points of the same elevation and the angle of the boundary plane. 


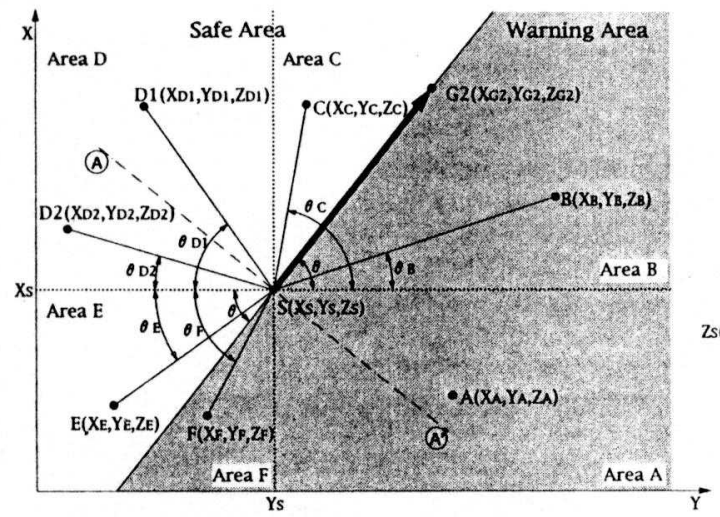

Figure 12 X-Y plane

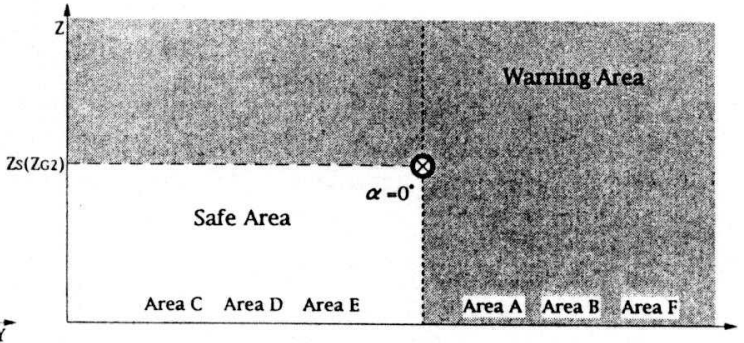

Figure $14 \mathrm{~A}-\mathrm{A}^{\prime}$ Section $\left(\alpha=0^{\circ}\right)$

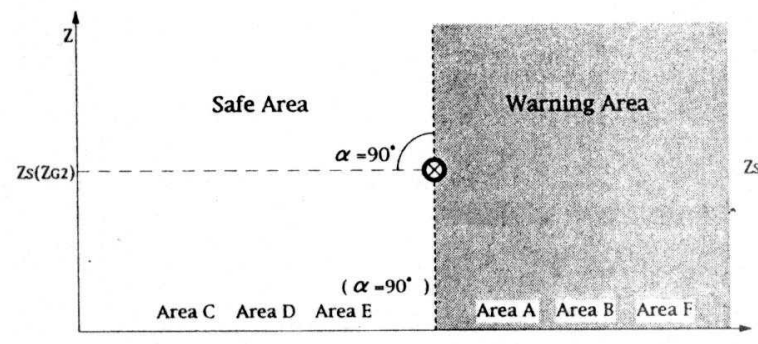

Figure $13 \mathrm{~A}-\mathrm{A}^{\prime}$ Section $\left(\alpha=90^{\circ}\right)$

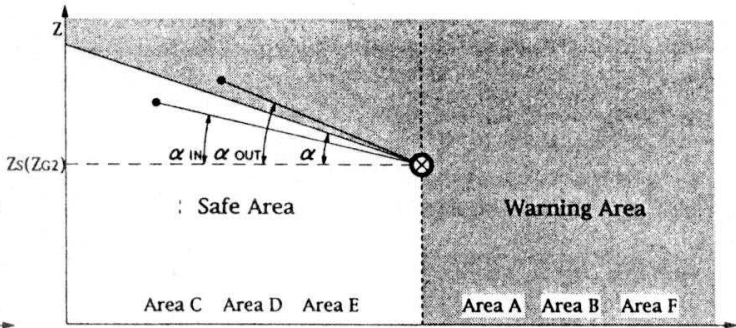

Figure $15 \mathrm{~A}-\mathrm{A}^{\prime}$ Section $\left(0^{\circ}<\alpha<90^{\circ}\right)$

\section{METHOD OF MANAGING THE WARNING AREA}

As Figure 16 shows, there are eight vector directions separating the area into safe and warning areas. Processing of the coordinates $(X, Y, Z)$ of the end of the boom that are transmitted from the total station depend on the type of vectors used to set the warning area. The method for checking whether or not the boom is in the safe area is explained below using SG2, which is one of the eight vectors. As Figure 12 shows, the $X-Y$ plane is divided into six by an extension line of the vector, a line going through $S$ and parallel to the $X$ axis, and a line going through $S$ and parallel to the $Y$ axis. The conditions of each area are shown below.

\begin{abstract}
$\overline{S G} 1: X_{S}=X_{G 1}, Y_{S}<Y_{G 1}$
SG2: $X_{s}<X_{G 2}, Y_{s}<Y_{G 2}$

$\overline{\mathrm{SG}} 3: X_{S}<X_{\mathrm{G}}, Y_{\mathrm{S}}=Y_{\mathrm{G} 3}$

$\overline{\mathrm{SG}} 5: X_{S}=X_{G 5}, Y_{S}>Y_{G 5}$ $\overline{\mathrm{SG} 6}: X_{\mathrm{S}}>X_{\mathrm{G} 6}, Y_{\mathrm{S}}>Y_{\mathrm{G} 6}$ $\overline{\mathrm{SG} 7}: X s>X_{G} 7, Y_{S}=Y_{G 7}$

SG4: $X s<X_{G 4}, Y_{S}>Y_{G 4}$

$\overline{\mathrm{SG} 8}: X_{\mathrm{S}}>X_{\mathrm{G} 8}, Y_{\mathrm{S}}<Y_{\mathrm{G} 8}$
\end{abstract}

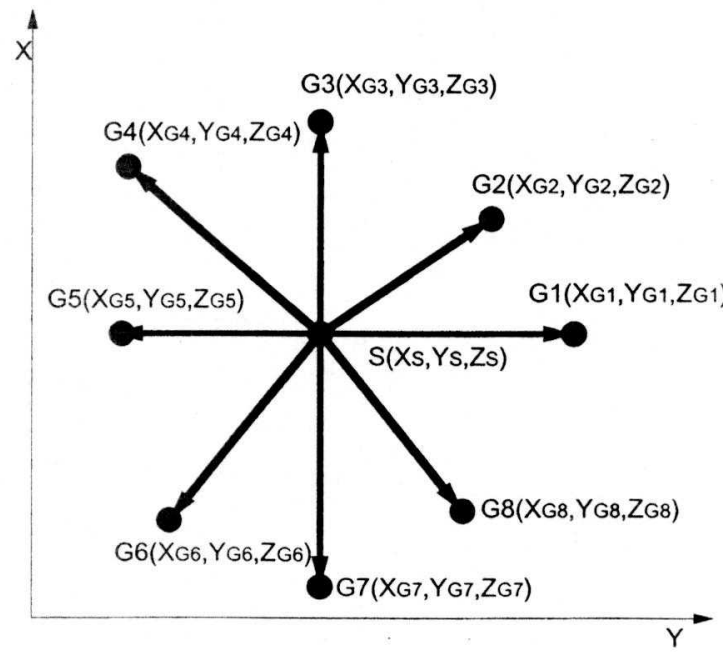

Figure 16 Vector types 
When the $X$ and $Y$ data of the end of the boom correspond to Area $A$, Area $B$, or Area $F$, the end of the boom is in the warning area. When the $X$ and $Y$ data of the end of the boom correspond Area C, Area D, or Area E, the angle $\alpha \mathrm{CDE}$ of the coordinate is calculated. When $\alpha>\alpha \operatorname{CDE}$ ( $\alpha$ is the set angle of the boundary plane), the end of the boom is judged to be in the safe area, but when $\alpha<\alpha$ CDE it is judged to be in the warning area. Figure 17 shows a simplified flow chart when the setting of the warning area is SG2. With this device, data transmitted from the total station every second is processed by repeating the number of settings of the warning area.

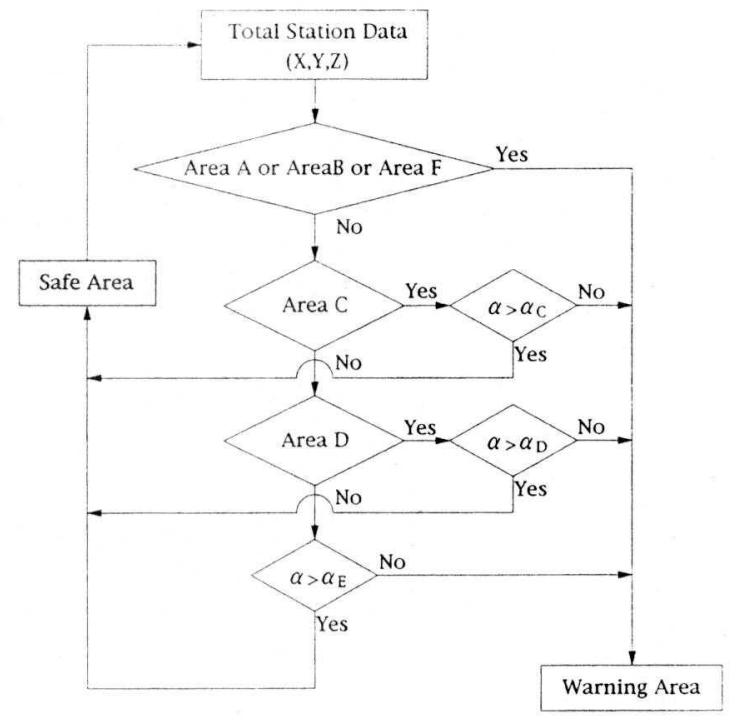

Figure 17 Flow chart

\section{APPLICATION AT A CONSTRUCTION SITE}

When an $\mathrm{N}$ airport terminal building is constructed, cranes operating at the site are controlled so that they do not break height restrictions stipulated in the civil aeronautics law.

(1)Name : $N$ airport terminal building

(2) Site area : $28,678 \mathrm{~m}^{2}$

(3)Building area : $17,227 \mathrm{~m}^{2}$

(4)Number of floor and height : 4 stories above the ground 2 stories under the ground Maximum height of $22.9 \mathrm{~m}$

(5)Structure : S(partially SRC)

(6)Use : Airport terminal building

(7)Construction period : From July 4,1994 to March 30,1996 
The restriction surfaces specified by civil aeronautics law are shown in Figure 18. An airport terminal site is subject to the restrictions of the transitional surfaces of the two landing zones. As a result of the height restrictions of these two transitional surfaces, the height restriction shapes for the site are as shown in Figure 19.

To convert the shape of the height restrictions to the coordinates of the control system, $X, Y$, and $Z$ axes are set as shown in Figure 20. Due to the relationships between the positions of the landing zones and the site, when two points of equal elevation are chosen from one transitional surface, $S_{A}$ and $G_{A}$ (from $A$ landing zone), and $\mathrm{SB}_{B}$ and $\mathrm{GB}_{\mathrm{B}}$ (from $\mathrm{B}$ landing zone) are as follows:

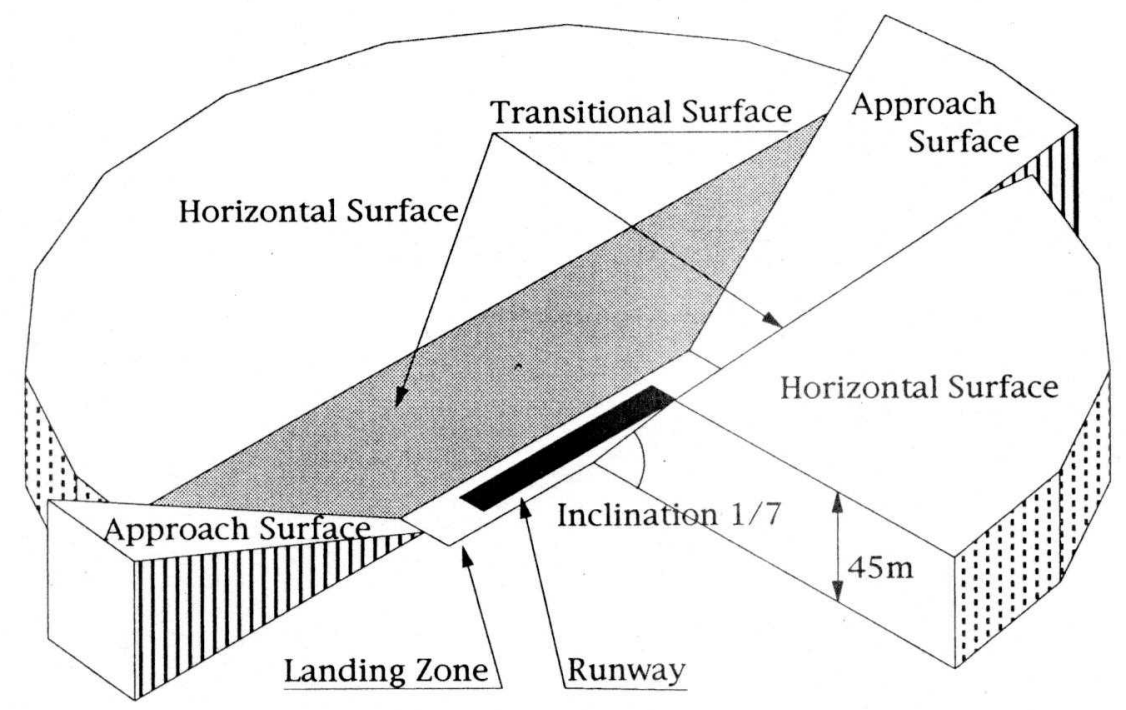

Figure 18 Civil aeronautics law

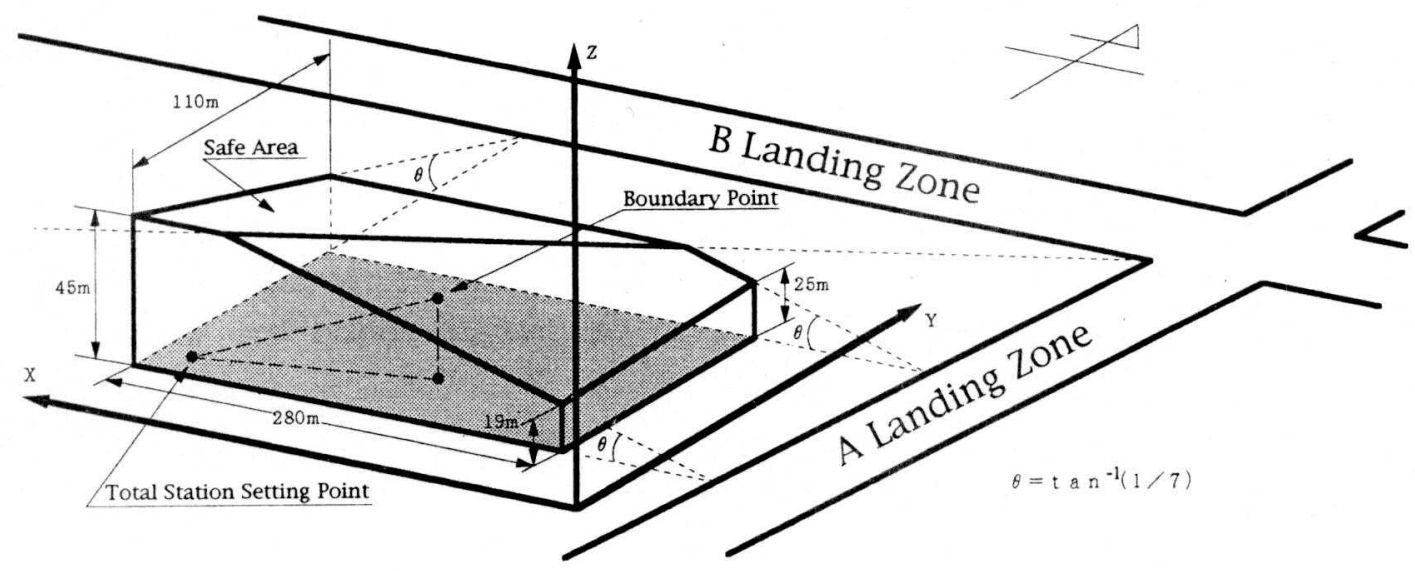

Figure 19 Airport height restrictions 


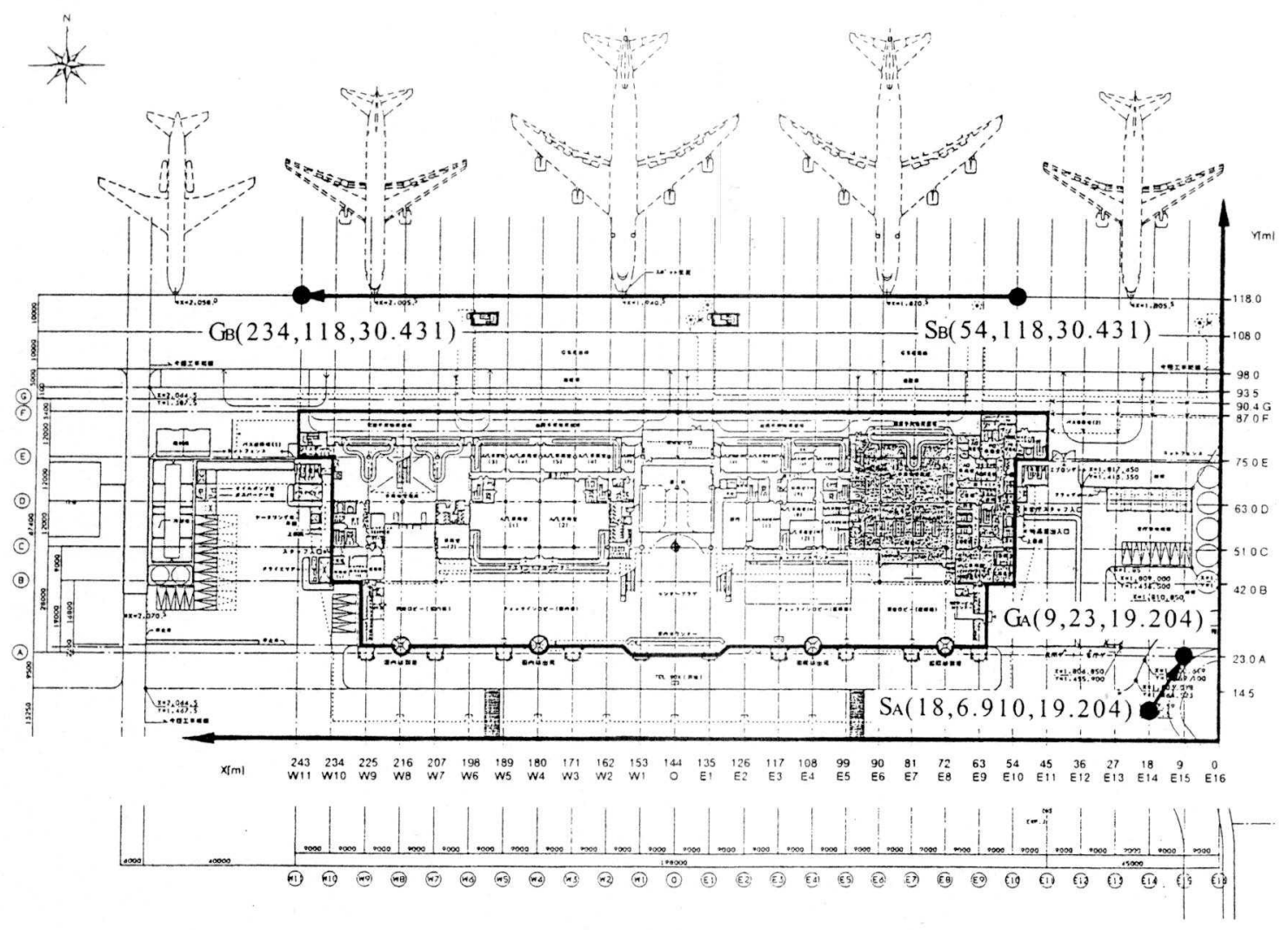

Figure 20 Coordinate system

By inputting two points on each of the two vectors and an inclination of $1 / 7$, the height restrictions made by the change surfaces can be set. As the inclination is input with an angle, a $1 / 7$ inclination is

$a=8.13^{\circ}$

With the above setting, the operating area could be managed even though its shape was complex.

\section{SYSTEM CHARACTERISTICS}

- Since installation of the device is easy no matter what the type of crane, all cranes can be managed automatically and surely.

- Even when the work site has a complex shape, the device can simply and accurately manage the operating area.

- Since the offset of the warning area can be freely changed and operations data can be output, they can be used for construction projects. 


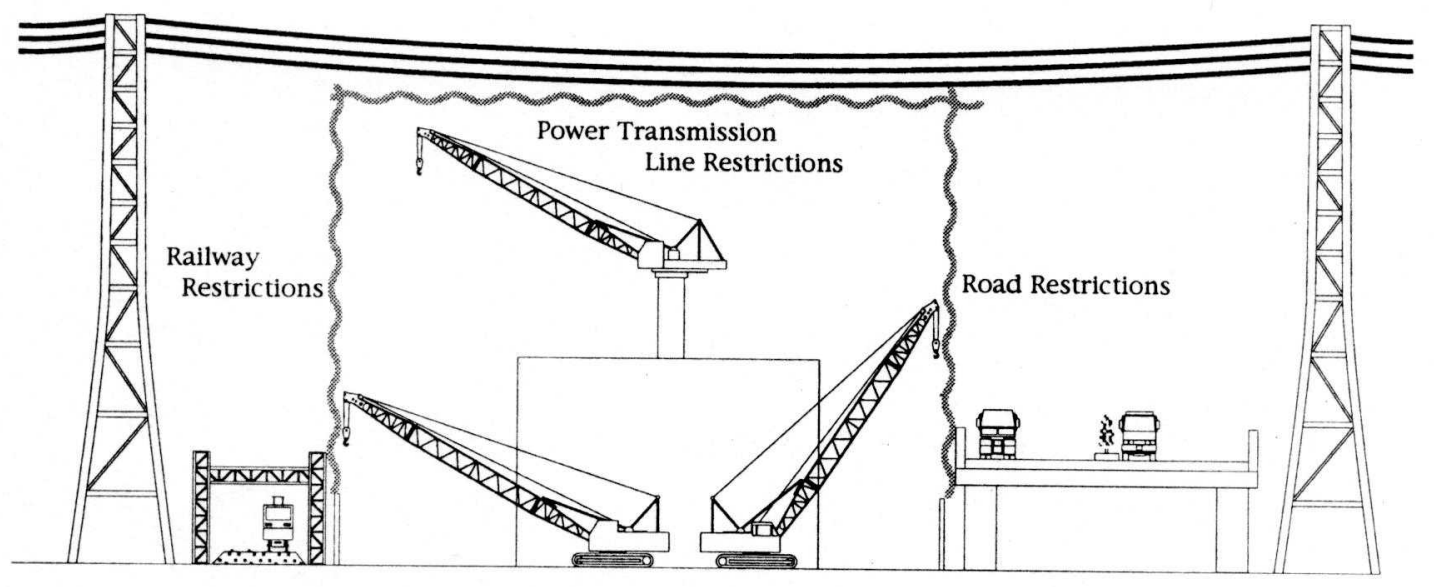

Figure 21 Example application

\section{CONCLUSION}

Since the system makes it easy to set the operating area of a crane simple, requiring only the installation of a prism at the end of the boom, it can be used for sites of any shape and for all types of crane. In the future we would like to devise more general applications for the system, improve crane safety, and to use the system for automatic crane operation. 